Table 2. Determination of $\bar{M} n$ of an Ionic Polystyrent osing Cellulose actiate Membranes Ca3/4; Benzene Solutions at $30^{\circ} \mathrm{C}$.

\begin{tabular}{|c|c|c|c|c|c|}
\hline \multirow{2}{*}{$\begin{array}{c}\text { Concentration } \\
\text { C } \\
\text { per cent } \\
(w / v)\end{array}$} & \multicolumn{4}{|c|}{ Equilibrium osmotic pressures } & \multirow{2}{*}{$\begin{array}{c}\text { Number aver- } \\
\text { age molecular } \\
\text { weight } \\
\bar{M}_{n}\end{array}$} \\
\hline & $\begin{array}{cc}\text { Rising } \\
h r & \text { Time } \\
(\mathrm{cm} .) & \text { (hr.) }\end{array}$ & $\begin{array}{c}\text { Fall } \\
\text { hf } \\
\text { (cm.) }\end{array}$ & $\begin{array}{l}\text { ing } \\
\text { Time } \\
\text { (hr.) }\end{array}$ & $\begin{array}{c}h \\
(\mathrm{~cm} .)\end{array}$ & \\
\hline $\begin{array}{l}0.100 \\
0.080 \\
0.060 \\
0.040 \\
0.020\end{array}$ & $\begin{array}{l}7 \cdot 64 \\
6 \cdot 15 \\
4 \cdot 56 \\
3 \cdot 39 \\
1 \cdot 60\end{array}$ & $\begin{array}{l}7 \cdot 54 \\
6 \cdot 33 \\
4 \cdot 59 \\
3 \cdot 36 \\
1 \cdot 54\end{array}$ & $\begin{array}{c}31 \\
112 \cdot 5 \\
28 \\
44 \cdot 5 \\
50\end{array}$ & $\begin{array}{l}7 \cdot 64 \\
6 \cdot 24 \\
4 \cdot 57 \\
3 \cdot 38 \\
1 \cdot 60\end{array}$ & $3,800 \pm 200$ \\
\hline
\end{tabular}

higher solvent permeabilities. The very selective membranes can be used for determining quite low molecular weights and in Table 2 are shown the results obtained using membrane $C A 3 / 4$ with an ionic polystyrene having $\bar{M}_{n}=3,800$. Unfortunately, while it is comparatively easy to make membranes such as $C A 2 / 58$, only a few membranes like $C A 1 / 68$ and $C A 3 / 4$ have so far been prepared. In these experiments benzene was used as solvent, but successful osmotic measurements have also been made in toluene and water.

The cellulose acetate used in the experiments was obtained from the British Drug Houses, Ltd.

I wish to thank Miss S. A. Monksfield and Miss H. M. Sankey for assistance with the experimental work. This work forms part of the research programme of the National Chemical Laboratory and is published by permission of the Director.

M. F. VAUGHaN

Department of Scientific and Industrial Research,

National Chemical Laboratory, Teddington, Middlesex.

${ }^{1}$ Vaughan, M. F., J. Polymer Sci. (in the press).

${ }^{2}$ Elford, W. J., Trans. Farad. Soc., 33, 1094 (1937).

\section{Liquid/Solid Content of Fats}

THe consistency of margarine and other commercial fats depends to a large extent on the relative amounts of liquid and solid fats present. The usual method for determining these values is by dilatation measurements and the dilatometer is used fairly considerably for this work. There are, however, certain inherent errors in this type of measurement. It is stated that the calculation of liquid/solid content from dilatometric data is either not possible with any degree of accuracy $^{1}$ or even that it is impossible ${ }^{2}$ with complex mixtures of glycerides. This arises from the fact that a prior knowledge of the glycerides present is required and that mathematical adjustment is needed to take account of the differert melting dilatations. Such prior knowledge is not always available.

We have recently found that the use of lowresolution nuclear magnetic resonance spectroscopy provides a new means for such determinations which eliminates many of the inherent errors of the dilatation method. In effect, use is made of the inherent disparity in the nuclear magnetic line-widths observed with liquids and solids. It is known that the shape of the hydrogen resonance line is influenced by the chemical and physical state of the sample and that the width is related to the mobility of the compound containing the hydrogen and to the field homogeneity. With solids the line-width is of the order of several gauss, while with liquids the line-width is very narrow and is determined by the inhomogeneity of the applied magnetic field ${ }^{3}$.
An example of the method adopted is illustrated by the determination of the liquid content of simple mixtures of known amounts of tristearin and triolein (tristearin does not form a solid solution in the triolein phase). A bridged-T nuclear magnetic resonance spectrometer was used 4 . The magnetic field was modulated at a sinusoidal frequency of about $40 \mathrm{c} / \mathrm{s}$. with a magnitude of about $30 \mathrm{milli}$ gauss, peak to peak. The line-width was determined by the inhomogeneity of the magnetic field and was about 100 milligauss at half-height. Under these conditions the derivative curve shows no signal due to the broad band of the solid, and a measure of the peak-to-peak height of the recorded derivative curve is a direct measure of the amount of liquid present. By comparing the peak-height for any of the mixtures with that for 100 per cent liquid, the liquid content can therefore be determined. Typical results are shown in Table 1. Similar work has also been carried out with other fat mixtures.

Table 1

\begin{tabular}{|c|c|}
\hline $\begin{array}{c}\text { Known percentage of } \\
\text { liquid glyceride }\end{array}$ & $\begin{array}{c}\text { Average percentage } \\
\text { found }\end{array}$ \\
\hline $75 \cdot 1$ & $74 \cdot 0$ \\
$50 \cdot 2$ & $51 \cdot 2$ \\
$25 \cdot 1$ & $25 \cdot 4$ \\
\hline
\end{tabular}

The new technique has the following advantages :

(a) Fats or mixtures may be examined in the state in which they are received, that is, without altering the structure by melting or crystallization.

(b) The results are independent of the particular composition of the fat, that is, no prior knowledge of the glycerides present is required.

(c) The results are independent of the polymorphic form of the solid present.

A full account of this work will be reported elsewhere.

Research Department,

D. Chapman

Unilever, Ltd.,

Port Sunlight.

R. E. RICHARDS

R. W. YORKE

Physical Chemistry Laboratory, Oxford.

Oct. 23.

${ }^{1}$ Bailey, A. E., "Melting and Solidification of Fats" (Interscience Pub., New York, 1950).

${ }^{2}$ Craig, M. B., Lundberg, W. D., and Geddes, W. F., J. Amer. Oil Chem. Soc., 29, 128 (1952).

"Andrew, F. R., "Nuclear Magnetic Resonance" (Cambridge Univ. Press, 1955).

${ }^{4}$ Richards, R. E., and Smith, J. A. S., Trans. Farad. Soc., 47, 1261 (1951). Pratt, L., and Riehards, R. E., ibid., 49, 744 (1953).

\section{Determination of Galactosediethylmercaptal and 3,6 Anhydrogalactosediethylmercaptal with the Anthrone and Seliwanoff Reagents}

Some pure 3,6 anhydro-L-galactose was required as standard to determine the concentration of this sugar in several algal polysaccharides. Efforts to prepare it in a crystalline form were unsuccessful. Therefore the standard solution was made up from the 3,6 anhydro-L-galactosediethylmercaptal. Unfortunately the ethylmercaptan liberated on acid hydrolysis of the mercaptal interfered with colour formation in the anthrone and Seliwanoff tests. A similar interference was obtained with the diphenylamine reagent ${ }^{1}$. A method was developed to obtain 